\title{
PID Control Design for Second Order Systems
}

\author{
RamaKoteswara Rao Alla ${ }^{\mathrm{a}}$, Lekyasri $\mathrm{N}^{\mathrm{b}}$, Rajani $\mathrm{K}^{\mathrm{c}}$ \\ ${ }^{a}$ Associate Professor, Electrical and Electronics Engineering Department, RVR \&JC College of \\ Engineering,Guntur, Andhra Pradesh-522019, India. \\ ${ }^{b}$ M.Tech Student, Electrical and Electronics Engineering Department, RVR \&JC College of Engineering, \\ Guntur,A.P,India. \\ 'Assistant Professor, EEE Department, Vignan's LARA Institute of Technology, Guntur,A.P,India.
}

Received: 13 March 2019; Accepted: 10 June 2019; Published: 08 July 2019

\begin{abstract}
The Proportional Integral Derivative (PID) controllers are most commonly used in industries to compensate several numbers of practical industrial processes by the virtue of their simplicity and robustness. Several tuning methods exist for parameter tuning of PID controller. In this paper PID control design for second order system has been done with various methods. The effectiveness of tuning methods has been compared based up on time response specifications.
\end{abstract}

Index Terms: PID controller, Tuning Methods, Time-Response Specifications.

(C) 2019 Published by MECS Publisher. Selection and/or peer review under responsibility of the Research Association of Mode rn Education and Computer Science

\section{Introduction}

In control systems there are two types of systems, one is open loop system and another one is closed loop system. Open loop system is termed as uncontrolled system due to the absence of feedback path. Whereas closed loop system is termed as controlled system. In closed loop systems output is controlled with the help of controller and it requires one or more feedback paths and its output will be stable at desired point. PID controller is best example for closed loop systems. In 1911, Elmer Sperry developed the real PID controller. In 1922, Nicholas minor sky published the first theoretical analysis of PID controller. PID controller plays a major role in control systems engineering from the past few decades [1]. PID controller has three parameters

* Corresponding author.

E-mail address: ramnitkkr@gmail.com 
likely Proportional-Integral- Derivative. The combined action of these three parameters is termed as PID controller. The working of proportional control is to optimize the steady state error by increasing the gain factor of proportional. Integral controller purpose is to eliminate the steady state error. Derivative controller main function is to decrease the overshoot and improves the system stability [2].

\author{
Nomenclature \\ PID Proportional Integral Derivative \\ ZN Ziegler Nichols \\ C-H-R Chien, Hrones and Reswich
}

These three individual parameters are treated as single entity in PID controller and their action improves the transient response of the system. Design of conventional PID controller are simple and easy to operate. The cost of PID controllers is low and with simple maintenance. It is widely used for industrial applications in various ways as feedback mechanism with robustness. For every application PID control systems are very unique with desired output point [6]. In previous days PID controllers have gone through analog electronics. After the invention of microprocessors, the process of all the PID controllers are done by microprocessors through digital circuits. PID controllers are also using in automation industries. Inbuilt instructions of PID controllers are in programmable logic controllers [6, 7]. PID controllers are conventionally used everywhere in the industrial applications of process control due to its reliability and flexibility.

The parameters of PID controllers are to be determined for the optimum response of the system to be controlled is referred as tuning of controller [1-4]. There are various tuning methods to found the three parameter values which gives the improvement in transient response of the system. Tuning methods are mainly classified as: (i) closed loop method (ii) open loop method. Closed loop method is nothing but operating controller in automatic state, while in open loop method in manual state. In this paper a closed loop method like Ziegler Nichols method and three open loop methods like Ziegler Nichols open loop method, C-H-R method, and Cohen Coon methods are considered to illustrate the system performance.

Yuan-Jay Wang [22] proposed a novel method to tune an optimal and robust PID controller for an open loop unstable FOPTD (First Order plus Time Delay) system. Here gain phase margin tester method and stability equation method has been used which is different from the traditional tuning methods. Against this method in [23] Yuan-Jay developed a novel alternative method which involved a graphical method to calculate all the feasible gain and phase margin specifications for robust PID controllers to stabilize a highly unstable FOPTD system. Unlike in [22] the author in [23] used both the stability equation method and parameter plane method to establish conditions of stability. Jan Cvejn in [24] developed a method to setup PI and PID controllers based on a stable FOPTD process model where dead time dynamics is manipulated without approximation. Here the main idea suggested by him was to use partial compensation which allowed using simple tuning rules which were a great advantage as the popularly used tuning rules were too complex.

The robust PID control of time delay systems usually requires the solution of complex non algebraic equations and approximating the time delay. But in [25] Wiesław Krajewski and Umberto Viaro used a graphical approach to the same. Such methods simple, as they were could not be applied to more complex systems. So in [26] G. Martelli, described the stability condition based on the Pontryagins Principle. The advantage was that its complexity was directly proportional to the number of process time constants. Such results were found to be valid for lower order plants having time delay but as the order of the plant increases the complexity also rises. In paper [27] these difficulty has been dealt with. The author De-Jin Wang suggested the stabilizing range to be provided in terms of Hermite Bahler theorem. Here the time constants of the plant are assumed to be arbitrary i.e. either positive or negative. Again as in [27] De-Jin Wang used the graphical method here. The PID controller can also be used to control Nonlinear Networked Control Systems with stochastic time delays as in Haikuo $\mathrm{He}$ and Xin $\mathrm{Du}$ [28]. Here they estimated the PI controller parameters by Parzen windows and Guassian Kernels and the convergence in mean square sense has been 
analysed for closed loop stochastic NCS's. As an extension of this in [29] Xiaoqian Guo and BinWu analysed the impact of network induced time delay on NCS and the weights of sensor controller time delay have been simulated. Furthermore the effect of plant parameters on the stability region of PID controllers was also presented.

The remaining part of the paper is organized as Section 2 describes the PID controller. In Section 3 tuning methods of PID controller have been discussed. Section 4 gives the system model and Section 5 deliberates the observation of simulation. Section 5 concludes the paper.

\section{PID CONTROLLER}

The basic structure of PID control system is shown in Fig.1. The difference of reference input $r(t)$ and desired output $y(t)$, i.e.e $(t)=r(t)-y(t)$.

Command signal is processed for the system by controlling this error through PID controller.

$$
U(t)=K_{P}\left[e(t)+\left(1 / T_{i}\right) \int_{-\infty}^{t} e d t+\tau_{d}(\mathrm{de} / \mathrm{dt})\right]
$$

Therefore the following transfer function describes the PID controller in continuous S-domain

$$
\begin{aligned}
& G_{C}=\mathrm{P}+\mathrm{I}+\mathrm{D} \\
& G_{C}=K_{P}+\frac{N_{d}}{s}+K_{d} s \\
& G_{C}=K_{P}\left(1+\frac{1}{T_{t}} s+\tau_{d} s\right)
\end{aligned}
$$

where

$$
\begin{gathered}
\tau_{d}=\text { Derivative time constant } \\
\tau_{f}=\text { Integral time constant } \\
K_{P}=\text { proportinal gain } \\
K_{l}=\text { Integration coefficient } \\
K_{D}=\text { Derivative time constant }
\end{gathered}
$$

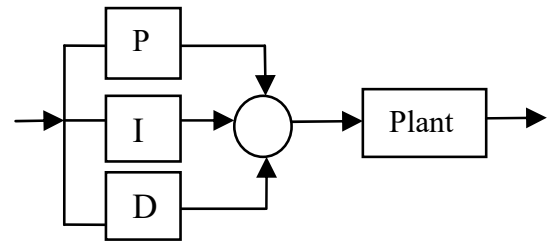

Fig.1. PID controller

According to Astrom and Hagglund [1], more than 95\% of the control loop is of the PID type. These type of controllers are popular because of their ease in operation , robust behaviour and easy maintenance. 
The effect of each parameter on the step response of the system is illustrated in Table 1.

Table 1 Effect of parameter on step response

\begin{tabular}{cccc}
\hline Parameters & Rising Time & Settling Time & Overshoot \\
\hline$k_{p}$ & Decreases & Increases & Small change \\
$k_{i}$ & Decrease & increase & Increase \\
$k_{d}$ & Small change & Decrease & Decrease \\
\hline
\end{tabular}

\section{TUNING METHODS OF PID CONTROLLER}

\section{A. Ziegler Nichols (ZN) method of tuning}

$\mathrm{ZN}$ methods are the most familiar method has two techniques to tune PID controller.

(i) $\mathrm{ZN}$ open loop method

(ii) $\mathrm{ZN}$ closed loop method

(i) $\mathrm{ZN}$ open loop technique:

This method is applied to the system along with unit step response to give the s-shaped curve as shown in Fig 2.This response of the system will be characterized by $\mathrm{L}$ and $\mathrm{T}$ parameters. These two parameters are reported from the tangential line to the system response of the unit step which is drawn at its inflection point [5][8] and the obtained parameters are calculated according to Table 2.

Table 2. Parameters of PID controller

\begin{tabular}{cccc}
\hline Controller & $K_{p}$ & $\tau_{i}$ & $\tau_{d}$ \\
\hline $\mathrm{P}$ & $\mathrm{T} / \mathrm{L}$ & - & - \\
$\mathrm{PI}$ & $0.9 \mathrm{~T} / \mathrm{L}$ & $\mathrm{L} / 0.3$ & - \\
$\mathrm{PID}$ & $1.2 \mathrm{~T} / \mathrm{L}$ & $2 \mathrm{~L}$ & $0.5 \mathrm{~L}$ \\
\hline
\end{tabular}




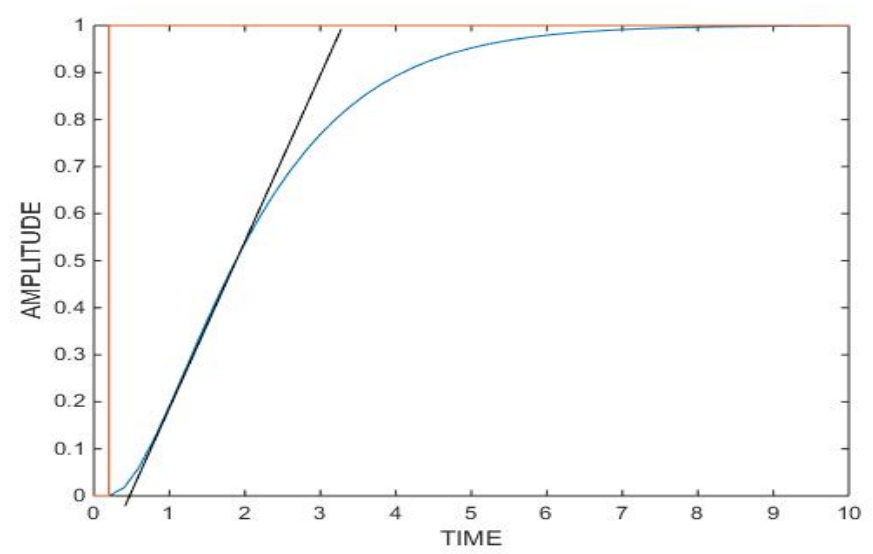

Fig.2. S-shaped curve with tangential line at inflection point

\section{B. ZN Closed loop technique}

In this technique, system is observed in the form of closed with controller and controller is tuned on the basis of rules given by increasing only $p$ controller value in PID controller. i.e. nothing but increasing proportional gain value is also known as critical gain $\left(K_{\mathrm{cr}}\right)$ and the time period of oscillations is referred as critical time period $\left(P_{c}\right)[5][8]$.These parameters are calculated in the below Table.3.

Table.3. PID parameter Tuning

\begin{tabular}{cccc}
\hline Controller & $K_{p}$ & $\tau_{i}$ & $\tau_{d}$ \\
\hline P & $0.5 K_{c r}$ & - & - \\
PI & $0.45 K_{c r}$ & $1.2 \frac{K_{p}}{P_{c}}$ & - \\
PID & $0.6 K_{c r}$ & $2 \frac{K_{p}}{P_{c}}$ & $K_{p} P_{c} / 0.8$ \\
\hline
\end{tabular}

\section{Chien,Hrones and Reswich( C-H-R) method of tuning}

Chien, Hrones and Reswich developed this method in 1952. Moderation of open loop ZN method is nothing but CHR method. This method ensures "quick response without over shoot", termed as" with $0 \%$ overshoot" and "quick response with $20 \%$ overshoot", termed as "with $20 \%$ overshoot"[9,10]. The tuning rules of this method are given in Table 4. 
Table 4. PID parameter tuning with overshoot level

\begin{tabular}{ccccccc}
\hline & \multicolumn{3}{c}{ WITH OVERSHOOT 0\% } & \multicolumn{3}{c}{ WITH OVERSHOOT 20\% } \\
\hline Controller & $K_{p}$ & $\tau_{i}$ & $\tau_{d}$ & $K_{p}$ & $\tau_{i}$ & $\tau_{d}$ \\
\hline P & $0.3 / \mathrm{a}$ & - & - & $0.7 / \mathrm{a}$ & - & - \\
PI & $0.35 / \mathrm{a}$ & $1.2 \mathrm{~T}$ & - & $0.6 / \mathrm{a}$ & $\mathrm{T}$ & - \\
PID & $0.6 / \mathrm{a}$ & $\mathrm{T}$ & $0.5 \mathrm{~L}$ & $0.9 / \mathrm{a}$ & $1.4 \mathrm{~T}$ & $0.47 \mathrm{~L}$ \\
\hline
\end{tabular}

\section{D.COHEN COON Method of Tuning}

The most sensitive method compared to open loop $\mathrm{ZN}$ method. The tuning procedure is similar as $\mathrm{ZN}$ open loop and obtained parameters $[9,11]$ from the graph will be calculated in below mentioned in Table 5 .

Table 5. PID Parameter tuning

\begin{tabular}{cccc}
\hline Controller & $K_{p}$ & $\tau_{i}$ & $\tau_{d}$ \\
\hline $\mathrm{P}$ & $\frac{1.03}{g_{p}}\left[\frac{\tau}{t_{d}}+0.34\right]$ & - & - \\
PI & $\frac{0.9}{g_{p}}\left[\frac{\tau}{t_{d}}+0.092\right]$ & $3.33 t_{d} \frac{\tau+0.092 t_{d}}{\tau+2.22 t_{d}}$ & - \\
PID & $\frac{1.35}{g_{p}}\left[\frac{\tau}{t_{d}}+0.185\right]$ & $2.5 t_{d} \frac{\tau+0.185 t_{d}}{\tau+0.611 t_{d}}$ & $0.37 t_{d} \frac{\tau}{\tau+0.185 t_{d}}$ \\
\hline
\end{tabular}

\section{SIMULINK RESULT AND OBSERVATION}

Here, second order systems is considered as

$$
G(S)=\frac{1}{s^{2}+3 S+1}
$$

By using different PID tuning methods the simulation results are summarized with their time response specifications such as rise time, settling time and overshoot. The parameters of PID controller used are also shown in Table.6. and Table.7.

The unit step response of the plant using Cohen coon method is given in Fig. 3 and the performance measures are given in Table. 6 


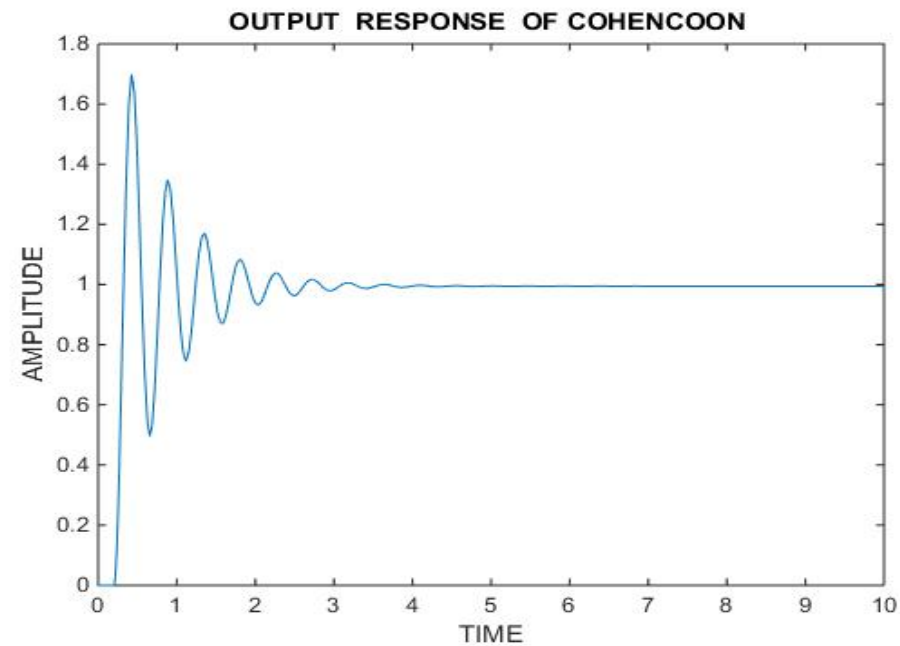

Fig. 3. Output response of system using Cohencoon method

Output response of the system using CHR method based PID tuning is given in Fig.4.The response is taken for $0 \%$ overshoot. The response of the system for $20 \%$ overshoot for the same method is given in Fig.5.The response of the system with PID control design using ZN open loop method is given in Fig.6 and ZN closed loop method is given in Fig.7.

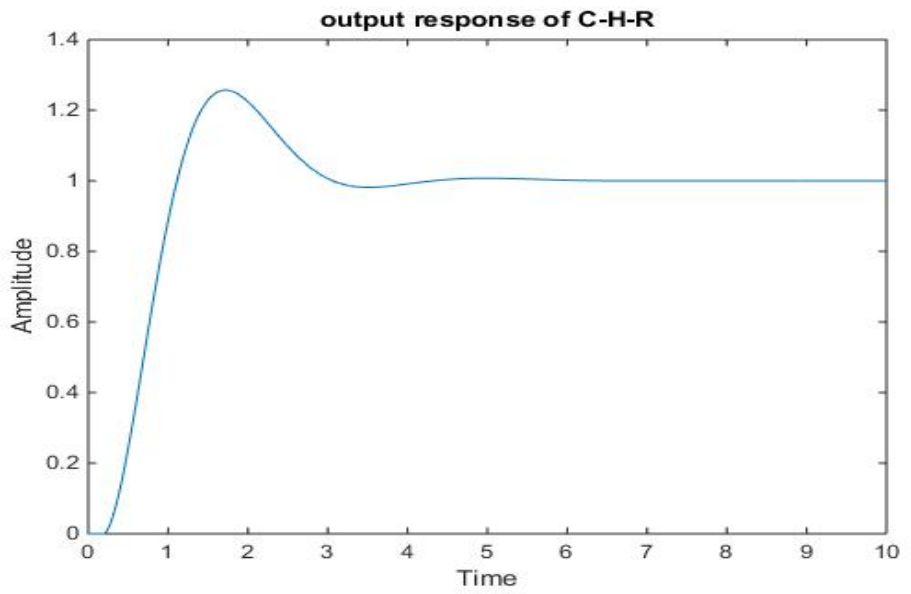

Fig.4. Output response of system with CHR with $0 \%$ overshoot 


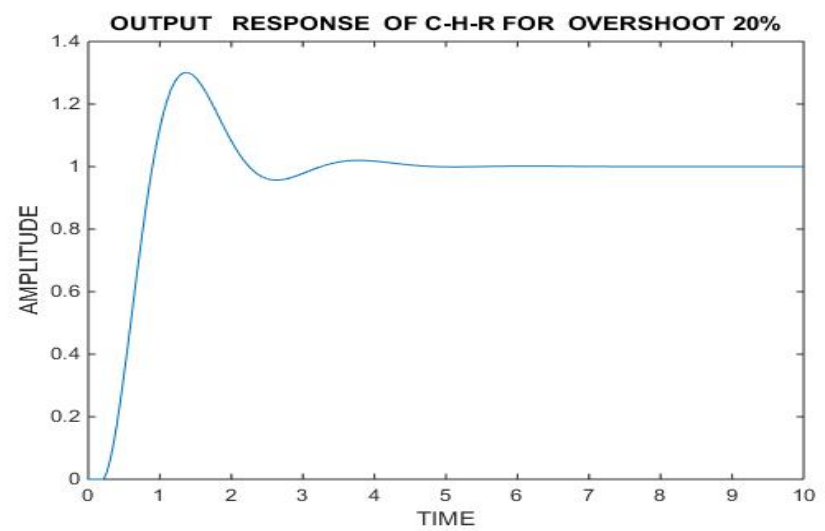

Fig.5. Output response of system with CHR with $20 \%$ overshoot.

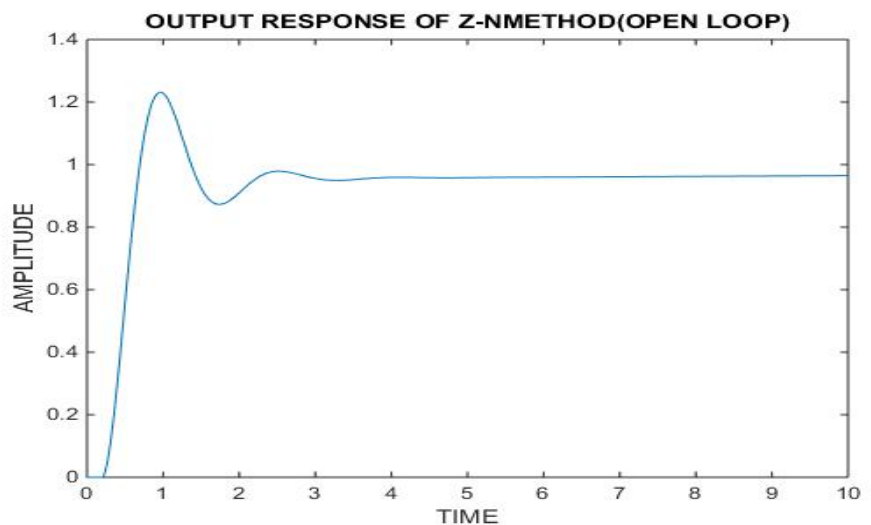

Fig.6. Output response of system with ZN open loop method

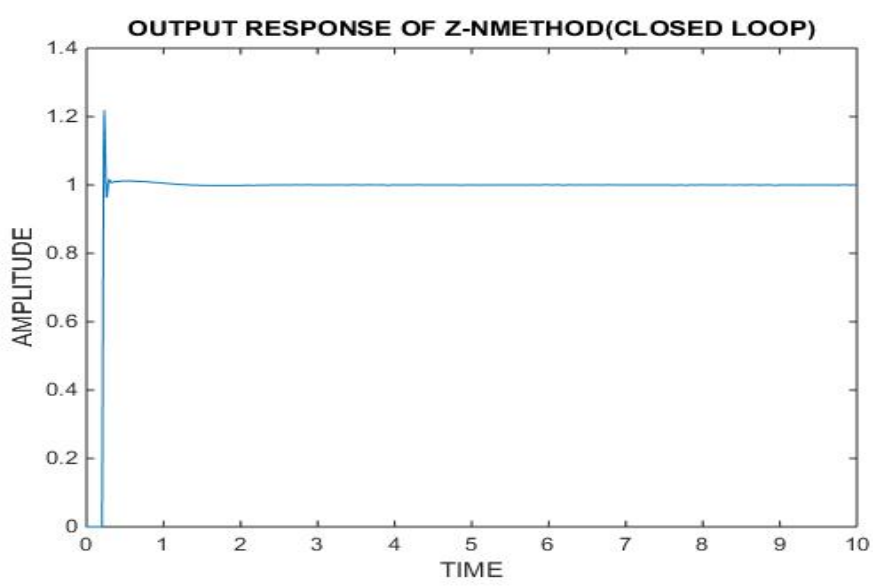

Fig.7. Output response of ZN closed loop method. 
The controller parameters calculated for various types of control deign are tabulated in Table 6. The performance of the system for various types of control design using time response specifications are tabulated in Table 7.

Table 6. Controller parameters for System with various methods

\begin{tabular}{cccc}
\hline METHOD & $\mathrm{K}_{\mathrm{P}}$ & $\mathrm{K}_{\mathrm{I}}$ & $\mathrm{K}_{\mathrm{D}}$ \\
\hline Z-NMETHOD (OPEN LOOP) & 18 & 0.6 & 0.15 \\
Z-N METHOD FOR(CLOSED LOOP) & 417 & 1250 & 125 \\
COHEN COON & 189.18 & 0.0498 & 0.00739 \\
C-H-R(0\%OVERSHOOT) & 6 & 4.6 & 0.15 \\
C-H-R(20\% OVERSHOOT) & 9 & 6.44 & 0.141 \\
\hline
\end{tabular}

. Table 7. Comparison of various transient parameters

\begin{tabular}{|c|c|c|c|c|}
\hline METHOD & $\begin{array}{l}\text { OVER } \\
\text { SHOOT }\end{array}$ & RISE TIME & $\begin{array}{c}\text { PEAK } \\
\text { RESPONSE }\end{array}$ & $\begin{array}{l}\text { SETTLING } \\
\text { TIME }\end{array}$ \\
\hline Z-NMETHOD (OPEN LOOP) & $23.8 \%$ & 0.339SEC & 1.24 & 27.7 SEC \\
\hline $\begin{array}{l}\text { Z-N METHOD FOR(CLOSED } \\
\text { LOOP) }\end{array}$ & $21.9 \%$ & $0.0134 \mathrm{SEC}$ & 1.22 & $0.0718 \mathrm{SEC}$ \\
\hline C-H-R(0\%OVERSHOOT) & $26.5 \%$ & $0.635 \mathrm{SEC}$ & 1.27 & 3.42 SEC \\
\hline C-H-R(20\% OVERSHOOT) & $31.1 \%$ & $0.481 \mathrm{SEC}$ & 1.31 & 3.74 SEC \\
\hline COHEN COON & $69.9 \%$ & $0.0826 \mathrm{SEC}$ & 1.7 & $0.0718 \mathrm{SEC}$ \\
\hline
\end{tabular}

From the results of various transient performance specifications, it can be observed that there is significant amount of improvement in results with $\mathrm{ZN}$ method of closed loop approach for some measures. Specifically, from the transient performance indices point of view, the ZN method of closed loop approach results in better performance in terms of settling time and CHR method of tuning gives better performance in terms of rise time. The $\mathrm{ZN}$ closed loop method gives superior results in terms of overshoot and settling time.

\section{CONCLUSION}

The majority of the modern control systems in industries are being controlled by the Proportional-Integral-Derivative (PID) controller. There are many methods available to set the parameters of the PID controllers. But the stability analysis of the systems using PID controllers still remain difficult and there are only a few existing results on the PID controller synthesis. The main aim is to tune the PID parameters of the controller. Paper describes PID controller design for a second order system. Tuning techniques were enforced and their performance is examined by considering a second order system. The performance of PID control design for the considered second order system has been evaluated with the help of time response specifications. From the results, it has been observed that the system exhibits large overshoot with Cohen -Coon tuning technique and largest settling time with Ziegler Nicholas open loop method. Ziegler 
Nicholas closed loop tuned PID exhibits less overshoot and settling time. Among all PID tuning techniques considered, it has been concluded that the Ziegler Nicholas closed loop tuned PID controller gives the best results for the second order system. The PID controller has some limitations such as, it works best for the processes that are linear and time invariant. This controller gives unsatisfactory results for the systems with nonlinearities, time variant and having uncertainties. In real applications, the proper tuning of the controller gains is still an open problem with this control. However, the future scope of this work includes tuning of PID controller for the systems with time delay.

\section{References}

[1] Astrom K.J., Hagglund T. PID controler: theory, design and tuning. 2nd ed. Research Triangle Park (NC): ISA; 1995.

[2] Nagrath J., Gopal M., "Control System Engineering”, New Age International Publications, 3rd Edition, 2002.

[3] J. G. Ziegler and N. B. Nichols, “Optimum Settings for Automatic Controllers,” Trans. ASME, Vol. 64, pp. 759-768, 1942.

[4] Venkatashankar, V.; Chidambaram, M. (1994). Design of P and PI controllers for unstable first-order plus time delay systems. International Journal of Control, 60(1), 137-144.

[5] RamaKoteswaraRao, A.; Choudhary, N.; Lather, J.S.; Pahuja, G.L. (2014), PIV and lead compensator design using Lambert $\mathrm{W}$ function for rotary motions of SRV02 plant. Proc.10th IEEE International Colloquium on Signal Processing \& its Applications (CSPA), Kula Lumpur, Malaysia, March 07-09:266-270.

[6] Normey-Rico, J.E.; Bordons C.; Camacho E.F. (1997). Improving the robustness of dead-time compensating PI controllers. Control Engineering Practice, 5(6), 801-810.

[7] Chen D, Seborg DE. "PI/PID controller design based on direct synthesis and disturbance rejection". IndEngChem Res 2002;41:4807-22.

[8] Chien IL, Fruehauf PS. "Consider IMC tuning to improve controller performance.” Chem Eng Prog 1990; 86:33-41.

[9] Kavdia Mahendra, Chidambaram M. "On-line controller tuning for unstable systems". ComputChem Eng 1996; 20:301-5.

[10] B.W. Bequette. Handbook of Process Control Modeling, Design and Simulation. pp. 285-307.

[11] Panda RC. "Synthesis of PID tuning rule using the desired closed-loop response." IndEngChem ,Res 2008;47(22):8684-92.

[12] Rivera DE, Morari M, Skogestad S. “Internal model control. 4. PID controller design.” IndEngChem Process Des Dev. 1986; 25:252-265.

[13] RamaKoteswaraRao, A., Lather, J.S., Pahuja, G.L., "Comparison Of PI Controller Performancefor First Order Systems with Time Delay”, Journal of Engineering Science \& Technology (JESTEC), Volume 12, Issue 4, April 2017.

[14] RamaKoteswaraRao A., Lather J.S., Pahuja G.L., "PI Controller Performance Analysis Using Lambert W Function Approach for First Order Systems with Time Delay", International Journal of Advanced Science and Technology, SERSC, Korea, vol. 86, pp. 1-8, January 2016.

[15] C.C Hang, W.K.Ho, LS Cao, “A comparison of two design methods for PID controller”, ISA transaction, vol.33, pp.147-151,July 1994.

[16] R. C. Panda, "Synthesis of PID Tuning Rule Using the Desired Closed-Loop Response", Ind. Eng. Chem. Res. vol. 47, pp.8684-8692, October 2008.

[17] V. Vijayan, R.C. Panda, "Design of PID controllers in double feedback loops for SISO systems with set-point filters", ISA Transactions, vol. 51, pp.514-521,July 2012.

[18] R D Kokate, L .M .Waghmare, "IMC-PID and Predictive Controller Design For a Shell and Tube Heat 
Exchanger" Emerging Trends in Engineering and Technology (ICETET), 2009 2nd International Conference on, vol., no., pp.1037,1041, 16-18 Dec. 2009.

[19] J. S. Guillermo, A. Datta and S.R Bhattacharyya, PID Controllers for Time-Delay Systems, Birkhauser Boston, 2005.

[20] Lee Y, Park S, Lee M, Brosilow C. "PID controller tuning for desired closed-loop responses for SISO systems." AIChE J. 1998; 44:106-115.

[21] V.Vijayan, Rames. C Panda "Design of PID controller in double feedback loops for SISO systems with set-point filters." ISA Transactions 51 (2012) 514-521.

[22] Yuan-Jay Wang, Tuning of Optimal and Robust PID Controller for Open-Loop Unstable First-Order plus Time Delay Systems, proceedings of 31st Chinese control conference,pp2459-2464,2012.

[23] Yuan-Jay, Calculation of All Robust PID Type Controllers for Unstable High-Order Time Delay Systems Based on Gain and Phase Margin Specifications, proceedings of 31st Chinese control conference,pp2775-2780,2012.

[24] Jan Cvejn, Sub-optimal PID controller settings for FOPDT systems with long dead time, Journal of Process Control 19,pp1486-1495,2009.

[25] Wiesław Krajewski, Umberto Viaro, "ON ROBUST PID CONTROL FOR TIME-DELAY PLANTS", 978-1-4673-2124-2/12, IEEE, pp540-545,2012.

[26] De-Jin Wang, Synthesis of PID controllers for high-order plants with time-delay, Journal of Process Control 19,pp1763-1768,2009.

[27] G. Martelli, Stability of PID-controlled second-order time-delay feedback systems, Automatica,Vol.45, pp2718-2722,2009.

[28] Junkang HAO, Haikuo He, Lilong DU, Xin DU, "A New PID Controller for nonlinear networked control systems with stochastic time delays", Fifth International Conference on Intelligent Computation Technology and Automation, pp467-470,2012.

[29] Xiaoqian Guo, BinWu, "The Impact of Time-delay on Networked Control System and Stability Region Analysis of PID Controllers", International Conference on Computer, Mechatronics, Control and Electronic Engineering (CMCE), pp163-166,2009.

[30] W. Zhang, "Optimal Design of the Refined Ziegler-Nichols Proportional-Integral-Derivative Controller for Stable and Unstable Processes with Time Delays", Ind. Eng. Chem. Res. ,vol.45, pp.1408-1419, January,2006.

[31] R. C. Panda, "Synthesis of PID Tuning Rule Using the Desired Closed-Loop Response", Ind. Eng. Chem. Res. vol. 47, pp.8684-8692, October 2008. 
Authors' Profiles

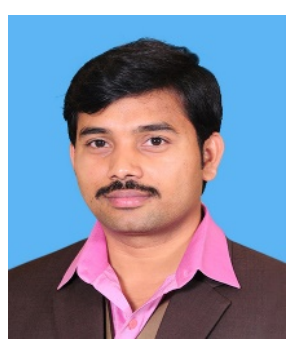

Dr.RamaKoteswara Rao Alla has graduated in Electrical and Electronics Engineering from JNTU Hyderabad. He did his M.Tech (Control Systems) and Ph.D. (Control Systems) in Electrical Engineering Department from National Institute of Technology Kurukshetra. Currently he is working as an Associate Professor in Electrical and Electronics Engineering Department, RVR \& JC college of Engineering, Guntur, Andhra Pradesh, India. His research interests include Control Systems, Time Delay Systems.

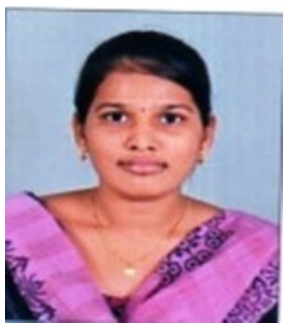

Ms.Nagaboina Lekhya sri received her Bachelor of Engineering degree from the department Electrical and Electronics Engineeringfrom Vasireddy Venkatadri Institute of Technology affiliated to Jawaharlal Nehru Technological University, Kakinada(JNTU-K). Guntur, India in 2017. Currently she is pursuing her Master Degree in Power Systems form R.V.R\&J.C College of Engineering,Guntur. Her areas of interest include Power systems ,Control systems.

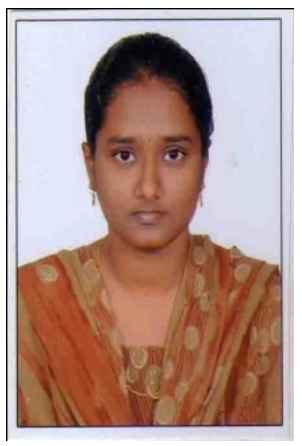

Ms.Kandipati Rajani has graduated in Electrical and Electronics Engineering from Vignan engineering college affiliated to JNTUK Kakinada. She did her M.E (Control Systems) in Electrical Engineering Department from Andhra University. Currently she is working as an Assistant Professor in Electrical and Electronics Engineering Department, Vignans lara institute of technology and sciences college, Guntur, Andhra Pradesh, India. Her research interests include Control Systems, Power electronics.

How to cite this paper: RamaKoteswara Rao Alla, Lekyasri N, Rajani K," PID Control Design for Second Order Systems", International Journal of Engineering and Manufacturing(IJEM), Vol.9, No.4, pp.45-56, 2019.DOI: 10.5815/ijem.2019.04.04 